\title{
Latitude, Sunlight, Vitamin D, and Childhood Food Allergy/Anaphylaxis
}

\author{
Raymond James Mullins • Carlos A. Camargo, Jr
}

Published online: 18 October 2011

(C) Springer Science+Business Media, LLC 2011

\begin{abstract}
Vitamin D is widely known for its role in bone metabolism, but this sterol hormone also has important immunomodulatory properties. Vitamin D is produced by the conversion of D3 in the skin following UVB exposure, or after ingestion of D2 or D3. At the extremes of latitude, there is insufficient UVB intensity in the autumn and winter months for adequate synthesis of vitamin $\mathrm{D}$ to occur. Growing evidence implicates vitamin D deficiency in early life in the pathogenesis of nonskeletal disorders (e. g., type 1 diabetes and multiple sclerosis) and, more recently, atopic disorders. Several studies have reported higher rates of food allergy/anaphylaxis or proxy measures at higher absolute
\end{abstract}

\section{R. J. Mullins $(\bowtie)$}

Medical School, Australian National University,

Canberra, ACT 0200, Australia

e-mail: rmullins@allergycapital.com.au

\section{R. J. Mullins}

Clinical Immunology, Faculty of Health, University of Canberra,

Canberra, ACT 2601, Australia

\section{R. J. Mullins}

Clinical Immunology and Allergy, John James Medical Centre,

Suite 1, 175 Strickland Crescent,

Deakin, ACT 2600, Australia

\section{A. Camargo Jr}

Department of Emergency Medicine and Division

of Rheumatology, Allergy, and Immunology,

Massachusetts General Hospital, Harvard Medical School,

Boston, MA, USA

e-mail: ccamargo@partners.org

\section{A. Camargo Jr}

Department of Medicine, Massachusetts General Hospital, Harvard Medical School,

Boston, MA, USA latitudes. Although causality remains to be determined, these studies suggest a possible role for sunlight and/or vitamin $\mathrm{D}$ in the pathogenesis of food allergy/anaphylaxis.

Keywords Food allergy · Anaphylaxis · Children · Sunlight $\cdot$ Vitamin D · Pathogenesis · Latitude

\section{Introduction}

Food allergy and anaphylaxis have become an increasing public and personal health burden in developed countries over the past decade, contributing to increased demand for specialty services [1], significant economic cost of care [2], and reduced quality of life for food-allergic children and their families [3]. Effective strategies for primary prevention are lacking, and secondary prevention is limited to strategies to reduce the risk of unintentional exposure. Although specific immunotherapy appears promising, it remains at the investigational stage [4]. While several factors have been proposed for the rise in food allergy (reviewed in [5]), the possibility that vitamin D status may play a pathogenic role has received recent attention. In this article, we review the evidence for and against a possible role of vitamin D status in allergic disease in general, and food allergy and anaphylaxis in particular. Because most food allergy begins in childhood, we have focused our review - when possible — on early-childhood.

\section{Vitamin D Physiology}

Vitamin D is widely known for its role in bone metabolism, but this sterol hormone also has important immunomodulatory properties. Vitamin D is produced by the conversion 
of D3 in the skin following UVB exposure, or after ingestion of $\mathrm{D} 2$ or $\mathrm{D} 3$. It is then converted in the liver to 25-hydroxyvitamin D $(25[\mathrm{OH}] \mathrm{D})$, which circulates bound to vitamin D-binding protein, and then is converted in the kidney to its active form, 1,25-dihydroxyvitamin D. This acts as a hormone (rather than vitamin) to increase calcium absorption in the intestine and regulate the differentiation and activation of osteoblasts and osteoclasts in the bone. Importantly, this conversion can also occur within cells of the immune system, such as activated $\mathrm{T}$ cells, dendritic cells, and possibly B cells, thus concentrating high levels of active vitamin $\mathrm{D}$ within the lymphoid microenvironment. Circulating levels of $25(\mathrm{OH}) \mathrm{D}$ are considered to be the best overall indicator of vitamin D status because levels reflect total vitamin D intake from sunlight exposure, dietary intake, and supplements. As little vitamin D is present naturally in most unfortified foods, levels of circulating 25 $(\mathrm{OH}) \mathrm{D}$ are largely determined by skin production that occurs in response to the variable amounts of UVB in sunlight [6].

\section{Vitamin D Deficiency}

Seasonal differences in UVB exposure result in lower 25 $(\mathrm{OH}) \mathrm{D}$ levels in autumn/winter months. At the extremes of latitude (eg, Europe, northern United States and Canada, southern Australia, and New Zealand), there is insufficient UVB intensity in the cooler months for adequate synthesis of $25(\mathrm{OH}) \mathrm{D}$ to occur, regardless of sun exposure [7]. Vitamin D insufficiency (defined as $25(\mathrm{OH}) \mathrm{D}<30 \mathrm{ng} / \mathrm{mL}$ $[<75 \mathrm{nmol} / \mathrm{L}]$ ) is thus common in these regions. Prevalence varies, but in many industrialized countries, up to $50 \%$ of the population has insufficient vitamin $\mathrm{D}$, with perhaps $10 \%$ being deficient (defined as $25[\mathrm{OH}] \mathrm{D}<10 \mathrm{ng} / \mathrm{mL}$ [ $<50 \mathrm{nmol} / \mathrm{L}]$ ] [8]. Almost $50 \%$ of US children were found to be vitamin D insufficient, and one in six were deficient in a recent US study [9], reflected in recent reports of rickets in the country [10]. Deficiency has also been shown to be common in pregnant women and neonates in many countries, including the United States [11], New Zealand [12], and Australia [13, 14].

Risk factors for vitamin D deficiency include darkcolored skin, skin coverage (due to religious, cultural, or health-related reasons), time spent indoors (e.g., immobility in older adults), malabsorption of dietary vitamin D precursors (e.g., celiac disease, inflammatory bowel disease), obesity (e.g., reduced mobility, sequestration of vitamin D in adipose tissue), sunscreen use, as well as the intensity of ambient UVB exposure (e.g., latitude and local weather conditions such as cloud cover or pollution, with lower ambient temperature potentially influencing time spent outside). Recent work suggests there likely is also a significant genetic contribution to variations in $25(\mathrm{OH}) \mathrm{D}$ levels secondary to polymorphisms in genes related to vitamin $\mathrm{D}$ metabolism that is equivalent in magnitude to that observed with seasonal differences between winter and summer $[15 \bullet \cdot$, which may in part explain why even those without obvious risk factors may be deficient $[16 \bullet \bullet, 17 \bullet \bullet]$. Trends to greater levels of vitamin D deficiency and insufficiency likely reflect several lifestyle changes in recent decades, particularly behavioral factors such as time spent indoors $[8,18]$. Low neonatal 25(OH)D levels have recognized adverse effects on bone health during earlychildhood [19]. In recent years, there has been an increasing appreciation that vitamin D deficiency in early life is implicated in the pathogenesis of many disorders (including type 1 diabetes and multiple sclerosis) and, more recently, atopic disorders, including food allergy [20-22].

\section{Geographic Variations in Anaphylaxis}

Estimates of anaphylaxis incidence vary widely, from 3.2 to 60 per 100,000 patient-years [23, 24], in part likely related to differences in the definition of anaphylaxis used; the research setting (hospital or community based); or whether calculations have been made based on actual episodes of anaphylaxis, estimates of the proportion of the population at risk (e.g., incidence of allergy to known triggers), or epinephrine autoinjector prescription rates $[25,26]$. One potential influence rarely examined in a systematic way is whether geographic variation may also occur. Based on the hypothesis linking early-life vitamin D status with recurrent wheezing and possibly asthma [27], Camargo and colleagues [28] examined geographic variation in epinephrine autoinjector prescription rates in the United States, demonstrating fourfold higher prescription rates in (the less sunny) northern United States compared with sunnier southern regions that could not be accounted for by measured demographic factors (Fig. 1). This novel finding raised the possibility of an etiologic role for sunlight/vitamin D status in food allergy, a major driver of epinephrine autoinjector prescriptions. Similar geographic patterns were previously observed for some other disorders, such as multiple sclerosis and type 1 diabetes [29]. These US epinephrine autoinjector findings were reproduced and extended in an Australian study by the authors that demonstrated that hospital anaphylaxis admission rates and epinephrine autoinjector prescription rates were significantly higher in less sunny southern regions of the country (Fig. 2) [30], although most prominent in children 0 to 4 years of age. Importantly, these trends could not be accounted for by demographic factors (e.g., socioeconomic status, access to medical care) and were most prominent in children 0 to 4 and 5 to 14 years of age - the age groups in which food 


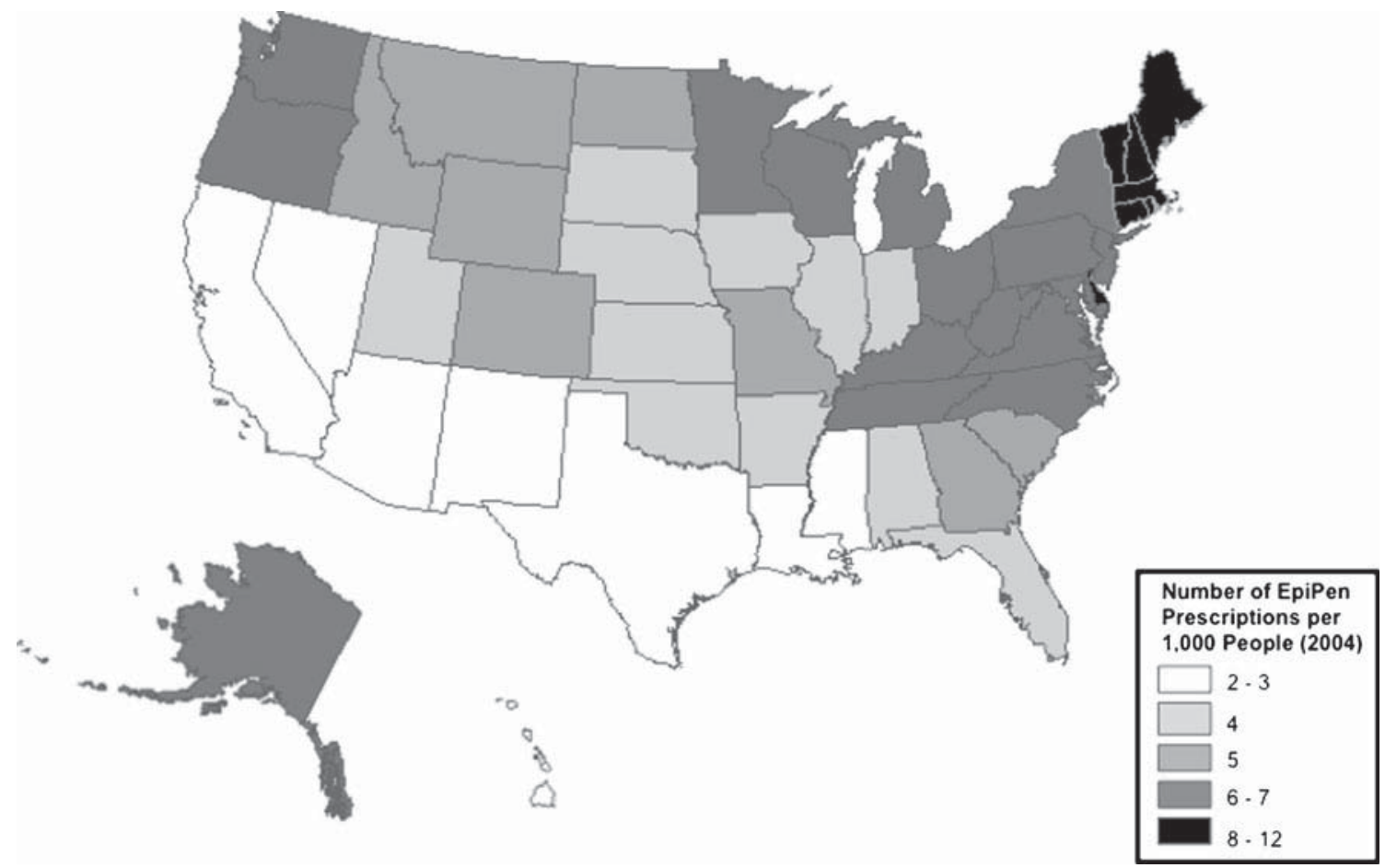

Fig. 1 Geographic variation in EpiPen (Dey Pharma, Basking Ridge, NJ) prescription rates in the United States. EpiPen prescription rates were higher in northern (less sunny) regions of the United States than southern (more sunlight) areas. (Reprinted from J Allergy Clin

allergy most commonly first presents and is the most common trigger of anaphylaxis [31]. Similar findings were described by Sheehan and colleagues [32], who examined hospital admissions and emergency department attendances coded as anaphylaxis in 24 pediatric hospitals in the United States. Specifically excluding sting anaphylaxis due to coding issues, overall anaphylaxis rates were higher in the 11 northern compared with the 13 southern hospitals $(0.88$ vs 0.63 per 1,000 encounters, respectively; $P<0.001)$. When reanalyzed by cause, admissions triggered by food, immunization or serum, or "other" causes (but not medication) were all more common in the northern hospitals. Specifically, the incidence of food anaphylaxis was almost double in the North compared with that in the South (0.31 vs 0.17 per 1000 encounters; RR, 1.81; 95\% CI, 1.66-1.98; $P<0.001$ ), although a separate study by the same group demonstrated that higher rates of sting anaphylaxis were more common in southern regions [33]. By contrast, no latitudinal pattern in self-reports of food allergy was found by Hughes and colleagues [34] in Australia, although these conclusions were based on only 14 older individuals aged 18 to 61 years. Most recently, Mulla and colleagues [35] compared anaphylaxis admission rates in New York (northern United States) and Florida (southern United States) and found twice the rate of
Immunol, volume 120, Camargo CA Jr, Clark S, Kaplan MS et al. Regional differences in EpiPen prescriptions in the United States: the potential role of vitamin D. Pages 131-136. Copyright 2007, with permission from Elsevier)

anaphylaxis admissions in New York residents in patients 0 to 19 years of age, with a reversal in older age groups. Taken as a whole, these studies suggest that latitudinal patterns may be influenced by age and cause of anaphylaxis, and that subanalysis of data is required for appropriate interpretation.

\section{Childhood Food Allergy}

Despite recent increases in anaphylaxis-related emergency department visits and hospital admissions in the United Kingdom [36], Australia [37], and United States [38]; more frequent anaphylaxis diagnoses in community-based studies $[39,40]$; and specific evidence of increased peanut allergy prevalence in birth cohort and community-based studies [41-43], risk factors for food allergy and anaphylaxis remain poorly defined. Hypotheses for these increases include changes in exposure to microbial products, topical sensitization, Caesarean section births, antacid medication use by infants, food processing methods, timing of introduction of allergenic food, or factors related to socioeconomic status or location of residence, as recently reviewed [5, 44-47]. That vitamin D status might also play a role in food allergy pathogenesis is suggested by a 
a

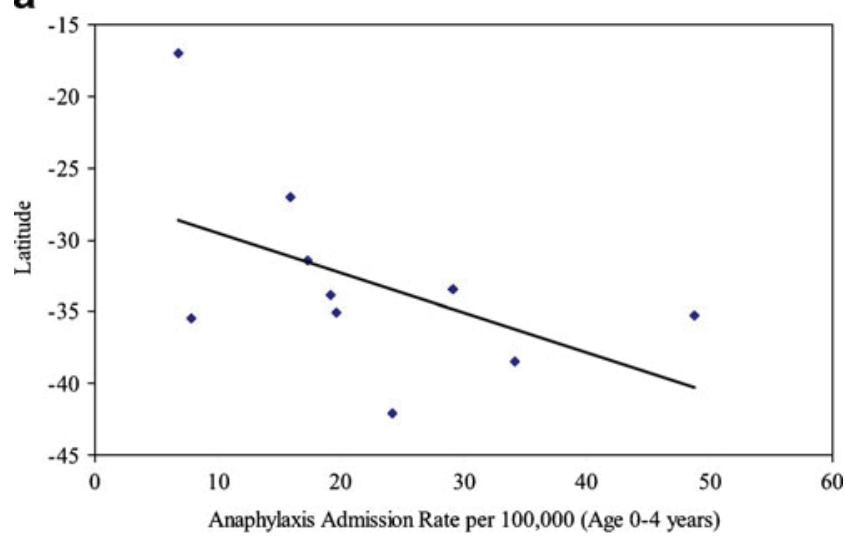

b

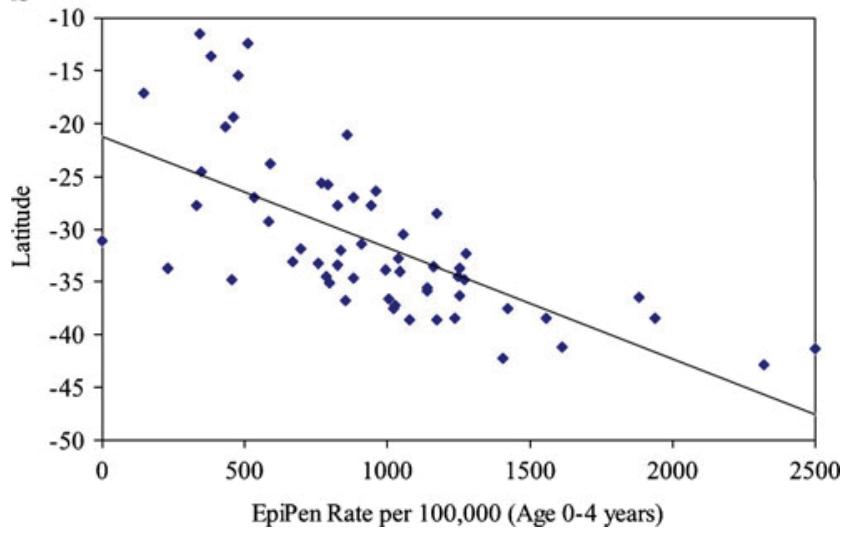

Fig. 2 Geographic variation in anaphylaxis admissions and EpiPen (Dey Pharma, Basking Ridge, NJ) prescription rates in Australian children aged 0 to 4 years. Anaphylaxis hospital admissions (a) and EpiPen prescriptions (b) were more common in southern (less sunlight) compared to northern regions (more sunlight) of Australia. (Reprinted from Ann Allergy Asthma Immunol, volume 103, Mullins RJ, Clark S, Camargo CA Jr. Regional variation in EpiPen prescriptions in Australia: more evidence for the vitamin Danaphylaxis hypothesis. Pages 488-495. Copyright 2009, with permission from Elsevier)

consistent inverse relationship between increasing latitude and proxy markers of food allergy prevalence, specifically higher rates of epinephrine autoinjector prescriptions and food allergy-related hospital admissions in less sunny regions of the United States and Australia [28, 30, 32] and higher infant hypoallergenic formula prescription rates in less sunny southern regions of Australia (Fig. 3) [48]. This hypothesis is reinforced by recent evidence of higher rates of food sensitization and physician-diagnosed FA in infants born in fall/winter compared with sunnier months in Europe [49, 50], the United States [51], and Australia (Fig. 4a) [52]; higher rates of food sensitization in infants born to mothers with low vitamin $\mathrm{D}$ intake during pregnancy [53]; and higher rates of food sensitization in children and adolescents (but not adults) with vitamin D deficiency $[54 \bullet \bullet]$.

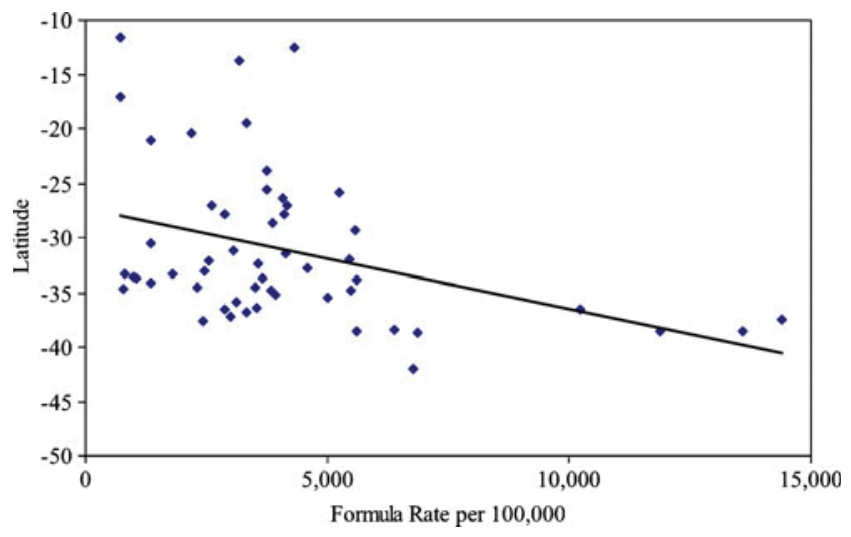

Fig. 3 Infant hypoallergenic formula prescription rates in Australian children aged 0 to 2 years as a function of latitude. Infant formula prescription rates were higher in southern (less sunlight) compared to northern regions (more sunlight) of Australia. (Reprinted from Pediatr Allergy Immunol, volume 21, Mullins RJ, Clark S, Camargo CA Jr. Regional variation in infant hypoallergenic formula prescriptions in Australia. Pages e413-e420. Copyright 2010, with permission from John Wiley and Sons)

\section{Vitamin D Status and Other Atopic Disorders}

Evidence that vitamin D status may be involved in the pathogenesis of atopic disorders is derived from epidemiologic and clinical studies and from in vitro studies examining the influence of vitamin D on immune function. Several studies have linked vitamin D deficiency with atopic dermatitis and recurrent wheezing in early life [27, 55, 56], two components of the "atopic March" of earlychildhood. Observational studies also have linked low vitamin D status with impaired lung capacity, increased bronchial reactivity, relatively poor asthma control, steroid unresponsiveness, and higher rates of asthma-related hospitalization, as recently reviewed [57-59]. Low intakes of vitamin D during pregnancy also have been linked to the presence and severity of allergic rhinitis in offspring [60]. Low 25(OH)D levels at age 6 and 14 years have been associated with higher rates of atopic disease in unselected community birth cohorts [61••]. One small, prospective, randomized, double-blind trial of vitamin D supplementation demonstrated a halving of infection-related asthma exacerbation [62・• ] and risk of wintertime influenza A [63]. Vitamin D status has been associated inversely with eczema severity [64], and sun exposure or vitamin D supplementation has been associated with clinical improvement in atopic eczema in small studies [55, 65].

By contrast, ecological studies examining latitudinal variation in disease prevalence (as a proxy marker of vitamin D status) have yielded conflicting results. Whereas the relationship between latitude and proxy markers of food allergy/anaphylaxis prevalence is relatively consistent (as discussed above), conflicting evidence of a relationship between latitude and prevalence of atopic eczema [29, 66, 

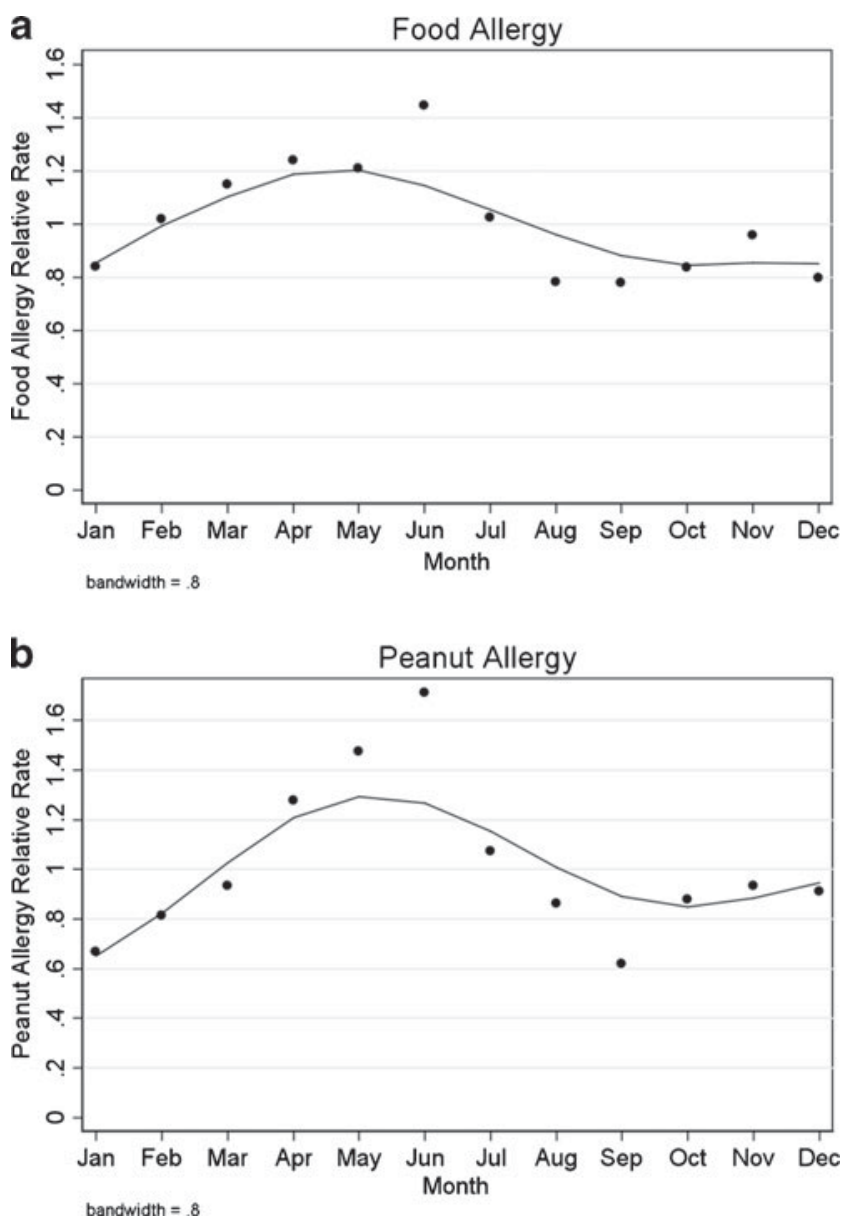

Fig. 4 Relative rates of food allergy by birth month in Australian children aged 0 to 4 years. The relative rates of food allergy (a) and peanut allergy (b) for Australian children aged 0 to 4 years born in the Australian Capital Territory are presented by birth month. Relative rates were calculated by adjusting for corresponding birth rates/month for the region, and were higher for children born in less sunnier months (March-August) than the rest of the year. (Reprinted from Pediatr Allergy Immunol, volume 2, Mullins RJ, Clarke S, Katelaris $\mathrm{CH}$ et al. Season of birth and childhood food allergy in Australia. Pages 583-589. Copyright 2011, with permission from John Wiley and Sons)

67] and allergic rhinitis [34, 67, 68] has been observed. These findings raise the possibility that if vitamin D status does play a role in the pathogenesis of atopic disease, its effect may not be uniform across all age groups or across all disorders classified as "atopic."

\section{Can Vitamin D Increase the Risk of Atopic Disease?}

Although correction of vitamin D insufficiency may offer health benefits, it is important to consider that observational data may reflect reverse causation. For example, the relationship between asthma severity and low vitamin D status might conceivably be secondary to those with more severe disease undertaking less outdoor activity. More importantly, it is necessary to be aware of published evidence that vitamin $\mathrm{D}$ supplementation might directly increase the risk of allergic disease (reviewed in [69]). Maternal 25(OH)D levels greater than $30 \mathrm{ng} / \mathrm{mL}$ during pregnancy have been associated with a higher risk of offspring eczema at 9 months and asthma at 9 years compared with children born to women with levels less than $10 \mathrm{ng} / \mathrm{mL}$ [70]. The potential for harmful effects from excessive vitamin D supplementation has been supported by the results of follow-up studies demonstrating increased risk of sensitization to inhalant or food allergen, allergic rhinitis, or asthma with vitamin D-containing cod liver oil supplements during infancy [71-73], which is contrary to the findings of other studies described above. In interpreting the results of these studies, however, it is important to be aware that cod liver oil contains vitamins $\mathrm{A}$ and $\mathrm{D}$, and that both vitamins bind the same nuclear retinoic $\mathrm{X}$ receptor. Thus, it is conceivable that the presence of both in the same preparation might antagonize the other's effects [74]. Most recently, Rothers and colleagues [75] demonstrated that both lower $(<10 \mathrm{ng} / \mathrm{mL})$ and higher $(\geq 20 \mathrm{ng} / \mathrm{mL})$ levels of cord blood 25(OH)D were associated with higher frequency of IgE sensitization to inhalants through to age 5 years compared with a reference group (10-19.9 nmol/L), although no association with increased risk of allergic rhinitis or asthma was observed [75]. In sum, the precise connection among sunlight, vitamin D, and allergic diseases, while intriguing, remains unclear.

\section{Vitamin D and Immune Function}

The biological plausibility of the "vitamin D-allergy hypothesis" is informed by growing evidence of the pleiotropic effects of vitamin D on the developing immune system. Recent studies have demonstrated associations between vitamin D receptor polymorphism and asthma risk [76]; between genetic variants in the vitamin D activation enzyme, vitamin D levels, and total IgE [77]; and between low vitamin $\mathrm{D}$ intake during pregnancy and higher cord blood interleukin-10 levels [78], known to suppress IgE production (reviewed in [74]). Furthermore, vitamin D receptor agonists have been shown to suppress allergen-specific IgE synthesis in vitro and in vivo [79, 80], modulate dendritic cell maturation to induce tolerogenic dendritic cells, induce regulatory $\mathrm{CD} 4{ }^{+} \mathrm{CD} 25^{+}$forkhead box $\mathrm{P} 3(\mathrm{FoxP} 3)^{+} \mathrm{T}$ cells, but also FoxP3-Treg1 cells expressing interleukin-10 [81••], thus affecting both T-helper type 1 (Th1) and Th2 cell function, as recently reviewed [74].

Although the potential effect of vitamin D on Th1/Th2 adaptive immune response is of interest, actions on the innate immune system are also important. For example, 
several studies have demonstrated an inverse relationship between vitamin $\mathrm{D}$ status and increased risk of respiratory tract infections [82.*0 and increased risk of wheezing in early life [27], [82••, 83] without any apparent effect on incident asthma at age 5 years $[82 \bullet$ ]. Vitamin D stimulates production of antibacterial peptides such as cathelicidin, which in experimental models is considered to have a role in enhancing resistance to infection and maintaining mucosal integrity (reviewed in [21]). It is conceivable that disrupted mucosal integrity and impaired tolerization (and perhaps altered gut microbiota) resulting from vitamin D deficiency may act synergistically with allergen exposure to increase the risk of sensitization at critical periods of immune development.

\section{Conclusions}

If sunlight/vitamin $\mathrm{D}$ status is one of the many factors playing a role in the pathogenesis of one or more allergic diseases, the relationship between sunlight/vitamin D status and risk may not be linear. As with any hormone, supraphysiologic vitamin D levels might also be harmful, as recently reviewed [77]. Furthermore, any impact of vitamin D status on disease risk may not be uniform across all age groups or applicable to all disorders traditionally classified as "atopic." If vitamin D is demonstrated to play a role in disease pathogenesis, it may force a reconsideration of data from published trials examining the relative benefits of breastfeeding (in which neonatal vitamin D status is dependent on that of the mother and thus variable) compared with infant formula feeding (in which vitamin D supplementation is routine). Further evidence of a possible role of sunlight/vitamin D status in pathogenesis, however, will require prospective cohort studies of neonatal $25(\mathrm{OH})$ $\mathrm{D}$ levels and subsequent risk of disease. If consistent associations are found, observational studies could be followed by randomized controlled trials to test causality more formally and monitor for adverse effects [84]. This would need to be undertaken in several age and ethnic groups and need to take account of the significant genetic variability of the response to dietary supplementation and metabolism of vitamin $\mathrm{D}$, as recently described [15••]. Long term, the potential survival benefits of sun exposure on vitamin $\mathrm{D}$ status need to be balanced with the known deleterious long-term consequences of increased risk of skin cancer (which generally occurs beyond reproductive age), which may force consideration of the relative merits of modest sun exposure with oral supplementation [85••]. Regardless of the potential contribution by sunlight/vitamin D status to the pathogenesis of food allergy/anaphylaxis, the frequency of vitamin $\mathrm{D}$ deficiency in pregnant women without obvious risk factors $[16 \bullet \cdot, 17 \bullet \cdot]$ and their neonates is a general health concern $[11,16 \bullet \bullet, 17 \bullet \bullet]$. This high frequency provides a rationale, in our opinion, to screen all pregnant women (not just high-risk groups) and to supplement individuals found to have vitamin D deficiency. The exact threshold for treatment and optimal regimen will require further study.

Disclosure Dr. Mullins has received unrestricted investigatorinitiated grants from Commonwealth Serum Laboratories Australia and Alphapharm Australia, Abbott Nutrition Australia, and the Ilhan Food Allergy Foundation.

Dr. Camargo has received investigator-initiated research grants from and served as a consultant for Dey Pharma and Sanofi-Aventis. Study sponsors had no input into the contents of this article.

\section{References}

Papers of particular interest, published recently, have been highlighted as:

•• Of major importance

1. Australasian Society for Clinical Immunology and Allergy. The economic impact of allergic disease in Australia: not to be sneezed at. ASCIA/Access Economics Report. November 2007 (http:// www.allergy.org.au/content/view/324/76/). Accessed May 2011.

2. Patel DA, Holdford DA, Edwards E, Carroll NV. Estimating the economic burden of food-induced allergic reactions and anaphylaxis in the United States. J Allergy Clin Immunol. 2011. doi:10.1016/j.jaci.2011.03.013.

3. Lieberman JA, Sicherer SH. Quality of life in food allergy. Curr Opin Allergy Clin Immunol. 2011;11:236-42.

4. Thyagarajan A, Varshney P, Jones SM, et al. Peanut oral immunotherapy is not ready for clinical use. J Allergy Clin Immunol. 2010;126:31-2.

5. Lack G. Epidemiologic risks for food allergy. J Allergy Clin Immunol. 2008;121:1331-6.

6. Holick MF. Vitamin D deficiency. N Engl J Med. 2007;357:26681.

7. Holick MF. Vitamin D: a millennium perspective. J Cell Biochem. 2003;88:296-307.

8. Ginde AA, Liu MC, Camargo CA Jr. Demographic differences and trends of vitamin D insufficiency in the US population, 19882004. Arch Intern Med. 2009;169:626-32.

9. Mansbach JM, Ginde AA, Camargo CA Jr. Serum 25hydroxyvitamin D levels among US children aged 1 to 11 years: do children need more vitamin D? Pediatrics. 2009;124:1404-10.

10. Weisberg P, Scanlon KS, Li R, Cogswell ME. Nutritional rickets among children in the United States: review of cases reported between 1986 and 2003. Am J Clin Nutr. 2004;80(suppl):1697S$705 \mathrm{~S}$.

11. Ginde AA, Sullivan AF, Mansbach JM, Camargo CA Jr. Vitamin $\mathrm{D}$ insufficiency in pregnant and nonpregnant women of childbearing age in the United States. Am J Obstet Gynecol. 2010;202:436.e1-8.

12. Camargo CA Jr, Ingham $\mathrm{T}$, Wickens $\mathrm{K}$, et al. The New Zealand asthma and allergy Cohort study group. Vitamin D status of newborns in New Zealand. Br J Nutr. 2010;50:259-61.

13. Eyles D, Anderson C, Ko P, et al. A sensitive LC/MS/MS assay of $25 \mathrm{OH}$ vitamin D3 and $25 \mathrm{OH}$ vitamin D2 in dried blood spots. Clin Chim Acta. 2009;403:145-51. 
14. Teale GR, Cunningham CE. Vitamin D deficiency is common among pregnant women in rural Victoria. Aust N Z J Obstes Gynacecol. 2010;50:259-61.

15. • Wang TJ, Zhang F, Richards JB et al. Common genetic determinants of vitamin D insufficiency: a genome-wide association study. Lancet. 2010; 376: 180-8. A genome-wide association study of almost 34,000 Europeans revealed that at least 4 major genes associated with cholesterol synthesis, hydroxylation, and vitamin $D$ transport were associated with marked variation in vitamin D levels.

16. -• Merewood A, Mehta SD, Grossman X et al. Widespread vitamin D deficiency in urban Massachusetts newborns and their mothers. Pediatrics. 2010; 125: 640-7. Of 489 maternal-infant pairs, more than $58 \%$ of infants and $36 \%$ of their mothers were vitamin $D$ deficient, defined as $25(\mathrm{OH}) \mathrm{D}$ less than $20 \mathrm{ng} / \mathrm{mL}$, with risk factors being higher maternal body mass index, skin color, and winter birth. Vitamin D sufficiency in the last two trimesters was associated with neonatal sufficiency.

17. • Perampalam S, Ganda K, Chow K et al. Vitamin D status and its predictive factors in pregnancy in 2 Australian populations. Aust N Z J Obstetr Gynaecol. 2011. doi:10.1111/j.1479828X.2011.01313.x. Vitamin D deficiency (defined as 25[OH]D levels $<25 \mathrm{nmol} / \mathrm{L}$ ) was seen in approximately $30 \%$ of pregnant women in two Australian cohorts, with risk factors being high body mass index, skin color, and winter birth. Oral vitamin $D$ supplements of 500 IU/d were provided inadequate protection against insufficiency.

18. Scragg R, Camargo CA Jr. Frequency of leisure-time physical activity and serum 25-hydroxyvitamin D levels in the US population: results from the Third National Health and Nutrition Examination Survey. Am J Epidemiol. 2008;168:577-86.

19. Javaid MK, Crozier SR, Harvey NC, et al. Princess Anne Hospital Study Group. Maternal vitamin D status during pregnancy and childhood bone mass at age 9 years: a longitudinal study. Lancet. 2006;367:36-43. Erratum in: Lancet. 2006; 367: 1486.

20. Thacher TD, Clarke BL. Vitamin D insufficiency. Mayo Clin Proc. 2011;86:50-60.

21. Vassallo MF, Camargo CA Jr. Potential mechanisms for the hypothesized link between sunshine, vitamin D and food allergy in children. J Allergy Clin Immunol. 2010;126:217-22.

22. Searing DA, Leung DY. Vitamin D in atopic dermatitis, asthma and allergic diseases. Immunol Allergy Clin North Am. 2010;30:397409.

23. Clark S, Camargo CA Jr. Epidemiology of anaphylaxis. Immunol Allergy Clin North Am. 2007;27:145-63.

24. Lieberman P, Camargo CA Jr, Bohlke K, et al. Epidemiology of anaphylaxis: findings of the American College of Allergy, Asthma and Immunology Epidemiology of Anaphylaxis Working Group. Ann Allergy Asthma Immunol. 2006;97:596-602.

25. Neugut AI, Ghatak AT, Miller RL. Anaphylaxis in the United States: an investigation into its epidemiology. Arch Intern Med. 2001;161:15-21.

26. Simons FE, Peterson S, Black CD. Epinephrine dispensing patterns for an out-of-hospital population: a novel approach to studying the epidemiology of anaphylaxis. J Allergy Clin Immunol. 2002;110:647-51.

27. Camargo CA Jr, Rifas-Shiman SL, Litonjua AA, et al. Maternal intake of vitamin $\mathrm{D}$ during pregnancy and risk of recurrent wheeze in children at 3 y of age. Am J Clin Nutr. 2007;85:788-95.

28. Camargo CA Jr, Clark S, Kaplan MS, et al. Regional differences in EpiPen prescriptions in the United States: the potential role of vitamin D. J Allergy Clin Immunol. 2007;120:131-6.

29. Staples JA, Ponsonby AL, Lim LL, McMichael AJ. Ecologic analysis of some immune-related disorders, including type 1 diabetes, in Australia: latitude, regional ultraviolet radiation, and disease prevalence. Environ Health Perspect. 2003;111:518-23.
30. Mullins RJ, Clark S, Camargo CA Jr. Regional variation in EpiPen prescriptions in Australia: more evidence for the vitamin D-anaphylaxis hypothesis. Annals Allergy Asthma Immunol. 2009;103:488-95.

31. Braganza SC, Acworth JP, Mckinnon DR, et al. Paediatric emergency department anaphylaxis: different patterns from adults. Arch Dis Child. 2006;91:159-63.

32. Sheehan WJ, Graham D, Ma L, et al. Higher incidence of pediatric anaphylaxis in northern areas of the United States. J Allergy Clin Immunol. 2009;124:850-2.

33. Sheehan WJ, Graham D, Ma L, et al. Higher incidence of pediatric anaphylaxis in southern areas of the United States. J Allergy Clin Immunol. 2009;123:S185.

34. Hughes AM, Lucas RM, Ponsonby AL, et al. The role of latitude, ultraviolet radiation exposure and vitamin $\mathrm{D}$ in childhood asthma and hayfever: an Australian multicenter study. Pediatr Allergy Immunol. 2011;22:327-33.

35. Mulla ZD, Lin RY, Simon MR. Perspectives on anaphylaxis epidemiology in the United States with new data and analyses. Curr Allergy Asthma Rep. 2011;11:37-44.

36. Gupta R, Sheikh A, Strachan DP, Anderson HR. Time trends in allergic disorders in the UK. Thorax. 2007;62:91-6.

37. Poulos LM, Waters AM, Correll PK, et al. Trends in hospitalizations for anaphylaxis, angioedema, and urticaria in Australia, 1993-1994 to 2004-2005. J Allergy Clin Immunol. 2007;120:878-84.

38. Rudders SA, Banerji A, Vassallo MF, et al. Trends in pediatric emergency department visits for food-induced anaphylaxis. J Allergy Clin Immunol. 2010;126:385-8.

39. Sheikh A, Hippisley-Cox J, Newton J, Fenty J. Trends in national incidence, lifetime prevalence and adrenaline prescribing for anaphylaxis in England. J R Soc Med. 2008;101:139-43.

40. Decker WW, Campbell RL, Manivannan V, et al. The etiology and incidence of anaphylaxis in Rochester, Minnesota: a report from the Rochester Epidemiology Project. J Allergy Clin Immunol. 2008;122:1161-5.

41. Grundy J, Matthews S, Bateman B, et al. Rising prevalence of allergy to peanut in children: data from 2 sequential cohorts. J Allergy Clin Immunol. 2002;110:784-9.

42. Mullins RJ, Dear K, Tang ML. Characteristics of childhood peanut allergy in the Australian Capital Territory 1995-2007. J Allergy Clin Immunol. 2009;123:689-93.

43. Sicherer SH, Muñoz-Furlong A, Godbold JH, Sampson HA. US prevalence of self-reported peanut, tree nut, and sesame allergy: 11-year follow-up. J Allergy Clin Immunol. 2010;125:1322-6.

44. Koplin JJ, Osborne NJ, Wake M, et al. Can early introduction of egg prevent egg allergy in infants? A population-based study. J Allergy Clin Immunol. 2010;126:807-13.

45. Prescott SL, Smith P, Tang M, et al. The importance of early complementary feeding in the development of oral tolerance: concerns and controversies. Pediatr Allergy Immunol. 2008;19:375-80.

46. Mullins RJ, Clark S, Camargo CA Jr. Socio-economic status, geographic remoteness and childhood food allergy and anaphylaxis in Australia. Clin Exp Allergy. 2010;40:1523-32.

47. Joseph CL, Ownby DR, Havstad SL, et al. Early complementary feeding and risk of food sensitization in a birth cohort. J Allergy Clin Immunol. 2011;127:1203-10.

48. Mullins RJ, Clark S, Camargo CA Jr. Regional variation in infant hypoallergenic formula prescriptions in Australia. Pediatr Allergy Immunol. 2010;21(2 Pt 2):e413-20.

49. Aalberse RC, Nieuwenhuys EJ, Hey M, Stapel SO. 'Horoscope effect' not only for seasonal but also for non-seasonal allergens. Clin Exp Allergy. 1992;22:1003-6.

50. Pyrhönen K, Läärä E, Hiltunen L, et al. Season of the first trimester of pregnancy predicts sensitisation to food allergens in childhood: a population-based cohort study from Finland. J Epidemiol Community Health. 2010. doi:10.1136/jech.2009.105411. 
51. Vassallo MF, Banerji AS, Rudders SA, et al. Season of birth is associated with food allergy in children. Annals Allergy Asthma Immunol. 2010;104:307-13.

52. Mullins RJ, Clarke S, Katelaris $\mathrm{CH}$, et al. Season of birth and childhood food allergy in Australia. Ped Allergy Immunol. 2011;22:583-9.

53. Nwaru BI, Ahonen S, Kaila M, et al. Maternal diet during pregnancy and allergic sensitization in the offspring by 5 yrs of age: a prospective cohort study. Pediatr Allergy Immunol. 2010;21(1 Pt 1):29-37.

54. • Sharief S, Jariwala S, Kumar J et al. Vitamin D levels and food and environmental allergies in the United States: results from the National Health and Nutrition Examination Survey 2005-2006. J Allergy Clin Immunol. 2011;127:1195-202. 25(OH)D deficiency (defined as $<15$ $\mathrm{ng} / \mathrm{mL}$ ) was associated with higher rates of sensitization to peanut and inhalant allergens in children and adolescents.

55. Sidbury R, Sullivan AF, Thadhani RI, Camargo CA Jr. Randomized controlled trial of vitamin $\mathrm{D}$ supplementation for winter-related atopic dermatitis in Boston: a pilot study. $\mathrm{Br} \mathrm{J}$ Dermatol. 2008;159:245-7.

56. Miyake Y, Sasaki S, Tanaka K, Hirota Y. Dairy food, calcium and vitamin $\mathrm{D}$ intake in pregnancy, and wheeze and eczema in infants. Eur Respir J. 2010;35:1228-34.

57. Camargo CA Jr, Ginde AA, Mansbach JM. Vitamin D, respiratory infections, and obstructive airway diseases. In: Holick MF, editor. Vitamin D: Physiology, molecular biology, and clinical applications. 2nd ed. Totowa: Humana Press; 2010. p. 997-1021.

58. Sandhu MS, Casale TB. The role of vitamin D in asthma. Ann Allergy Asthma Immunol. 2010;105:191-9.

59. Brehm JM, Schuemann B, Fuhlbrigge AL, et al. Childhood Asthma Management Program Research Group. Serum vitamin D levels and severe asthma exacerbations in the Childhood Asthma Management Program study. J Allergy Clin Immunol. 2010;126:52-8.

60. Erkkola M, Kailaw M, Nwaruz BI, et al. Maternal vitamin D intake during pregnancy is inversely associated with asthma and allergic rhinitis in 5-year-old children. Clin Exp Allergy. 2009;39:875-82.

61. • Hollams EM, Hart PH, Holt BJ et al. Vitamin D and atopy and asthma phenotypes in children: a longitudinal cohort study. Eur Respir J. 2011; in press. Low 25(OH)D levels at age 6 and 14 years were associated with higher rates of sensitization to inhalant allergens in an unselected community birth cohort.

62. •- Majak P, Olszowiec-Chlebna M, Smejda K, Stelmach I. Vitamin D supplementation in children may prevent asthma exacerbation triggered by acute respiratory infection. J Allergy Clin Immunol. 2011;127:1294-6. In a double-blind, randomized trial of budesonide alone or budesonide plus vitamin D supplements in 48 patients aged 5 to 18 years, vitamin D-supplemented patients had significant improvements in forced expiratory volume in 1 second and fewer infection-related exacerbations in asthma.

63. Urashima M, Segawa T, Okazaki M, et al. Randomized trial of vitamin $\mathrm{D}$ supplementation to prevent seasonal influenza $\mathrm{A}$ in schoolchildren. Am J Clin Nutr. 2010;91:1255-60.

64. Peroni DG, Piacentini GL, Cametti E, et al. Correlation between serum 25-hydroxyvitamin $\mathrm{D}$ levels and severity of atopic dermatitis in children. Br J Dermatol. 2011;164(5):1078-82. doi:10.1111/j.1365-2133.2010.10147.x.

65. Solé D, Wandalsen GF, Camelo-Nunes IC, Naspitz CK. ISAACBrazilian Group. Prevalence of symptoms of asthma, rhinitis, and atopic eczema among Brazilian children and adolescents identified by the International Study of Asthma and Allergies in Childhood (ISAAC) — phase 3. J Pediatr (Rio J). 2006;82:341-6.

66. Fsadni P, Fsadni C, Fava S, Montefort S. Correlation of worldwide incidence of type 1 diabetes (Diamond) with prevalence of asthma and atopic eczema (ISAAC). Clin Respir J. 2011. doi:10.1111/j.1752-699X.2011.00239.x.
67. Weiland SK, Hüsing A, Strachan DP, et al. ISAAC Phase One Study Group. Climate and the prevalence of symptoms of asthma, allergic rhinitis, and atopic eczema in children. Occup Environ Med. 2004;61:609-15.

68. Wjst M, Dharmage S, André E, et al. Latitude, birth date, and allergy. PLoS Med. 2005;2(10):e294.

69. Wjst M. Introduction of oral vitamin D supplementation and the rise of the allergy pandemic. Allergy Asthma Clin Immunol. 2009;5:8.

70. Gale CR, Robinson SM, Harvey NC, et al. Princess Anne Hospital Study Group. Maternal vitamin D status during pregnancy and child outcomes. Eur J Clin Nutr. 2008;62:68-77.

71. Hyppönen E, Sovio U, Wjst $\mathrm{M}$, et al. Infant vitamin $\mathrm{d}$ supplementation and allergic conditions in adulthood: northern Finland birth cohort 1966. Ann N Y Acad Sci. 2004;1037:84-95.

72. Kull I, Bergström A, Melén E, et al. Early-life supplementation of vitamins $\mathrm{A}$ and $\mathrm{D}$, in water-soluble form or in peanut oil, and allergic diseases during childhood. J Allergy Clin Immunol. 2006;118:1299-304.

73. de Montis G, Truong M, Toussaint B, et al. Peanut sensitization and oily solution vitamin preparations. Arch Pediatr. 1995;2:25-8.

74. Moro JR, Iwata M, von Andriano UH. Vitamin effects on the immune system: vitamins $\mathrm{A}$ and $\mathrm{D}$ take centre stage. Nat Rev Immunol. 2008;8:685-98.

75. Rothers J, Wright AL, Stern DA et al. Cord blood 25 hydroxyvitamin $\mathrm{D}$ levels are associated with aeroallergen sensitization in children from Tucson, Arizona. J Allergy Clin. Immunol 2011 (in press).

76. Raby BA, Lazarus R, Silverman EK, et al. Association of vitamin D receptor gene polymorphisms with childhood and adult asthma. Am J Respir Crit Care Med. 2004;170:1057-65.

77. Hyppönen E, Berry DJ, Wjst M, Power C. Serum 25hydroxyvitamin $\mathrm{D}$ and $\mathrm{IgE}$ - a significant but nonlinear relationship. Allergy. 2009;64:613-20.

78. Zittermann A, Dembinski J, Stehle P. Low vitamin D status is associated with low cord blood levels of the immunosuppressive cytokine interleukin-10. Pediatr Allergy Immunol. 2004;15:242-6.

79. Hartmann B, Heine G, Babina M, et al. Targeting the vitamin D receptor inhibits the $\mathrm{B}$ cell-dependent allergic immune response. Allergy. 2011. doi:10.1111/j.1398-9995.2010.02513.x.

80. Milovanovic M, Heine G, Hallatschek W, et al. Vitamin D receptor binds to the $\varepsilon$ germline gene promoter and exhibits transrepressive activity. J Allergy Clin Immunol. 2010;126:1016-23.

81. • van der Aar AM, Sibiryak DS, Bakdash G et al. Vitamin D3 targets epidermal and dermal dendritic cells for induction of distinct regulatory $\mathrm{T}$ cells. J Allergy Clin Immunol. 2011. doi:10.1016/j.jaci.2011.01.068. In this in vitro study, vitamin D3-primed human dendritic cells induced tolerogenic regulatory T cells expressing interleukin-10.

82. • Camargo CA Jr, Ingham T, Wickens K et al. New Zealand Asthma and Allergy Cohort Study Group. Cord-blood 25hydroxyvitamin D levels and risk of respiratory infection, wheezing, and asthma. Pediatrics. 2011;127:e180-7. doi: 10.1542/peds.2010-0442. Low cord blood 25(OH)D levels were associated with increased risk of respiratory infection and wheezing in early life, but not incident asthma at age 5 years.

83. Devereux G, Litonjua AA, Turner SW, et al. Maternal vitamin D intake during pregnancy and early childhood wheezing. Am J Clin Nutr. 2007;85:853-9.

84. Roth DE. Vitamin D supplementation during pregnancy: safety considerations in the design and interpretation of clinical trials. J Perinatol. 2011;31(7):449-59. doi:10.1038/jp.2010.203.

85. • Stalgis-Bilinski KL, Boyages J, Salisbury EL et al. Burning daylight: balancing vitamin $\mathrm{D}$ requirements with sensible sun exposure. Med J Aust. 2011;194:345-8. This examination of sun exposure and vitamin D production showed it would be difficult to obtain sufficient vitamin D without exposing the skin to levels of UVR at which sun protection is currently recommended. 